\title{
Study on Temperature Control and Crack Prevention of Mass Concrete for Large Powerhouse Constructed in Cold Area
}

\author{
Qiaorong Sun ${ }^{1}$, Bingyong Ding ${ }^{2}$, Zaixin Zheng ${ }^{2}$, Running Du ${ }^{2}$, and Sheng Qiang ${ }^{1,3, *}$ \\ ${ }^{1}$ College of Water Conservancy and Hydropower, Hohai University, 210098 Nanjing, China \\ ${ }^{2}$ HydroChina Huadong Engieering Corporation Limited, 311122 Hangzhou, China \\ ${ }^{3}$ College of Civil Engineering, Xijing University, 710123 Xi'an, China
}

\begin{abstract}
Due to complex structure, large scale, and cold climate, the temperature field and stress field during construction of BoYi Station is different with ordinary mass concrete. Therefore the corresponding crack prevention method must be explored. In order to simulate the complicated construction course, cold climate, multiple materials and unusual structure, a finite element program is adopted. In 5 numerical simulation cases, different temperature control methods are tried to decrease the tensile stress of mass concrete. Based on the simulation analysis and combined with the engineering experience, the scheme and indexes of temperature control and crack prevention are recommended. The mainly measures are controlling pouring temperature, insulation of concrete surface, pipe cooling, block partition and extra steel bar reinforcement. The values of temperature indexes are sharply lower than that of ordinary hydropower station mass concrete. The suggested measures and indexes in this paper, which are various with season, structure position and material, may provide some reference to similar large hydropower station workshop in cold area.
\end{abstract}

Keywords: Mass concrete, Cold area, Hydropower station, Temperature control and crack prevention

\section{Introduction}

The existence and development of concrete cracks will not only affect the appearance of the building and weaken the bearing capacity of the corresponding members to a certain extent, but also cause leakage, accelerate the carbonization of concrete, reduce the corrosion resistance of concrete, decrease the lasting strength, even cause the foundation seepage deformation, endanger the building normal use and shorten the building service life.

The structure size of BY station is large. The total amount of main body concrete is about $340,000 \mathrm{~m}^{3}$, among of the mass concrete is about $200,000 \mathrm{~m}^{3}$. The structure shape and construction procedure of the hydropower station are complicated. At the station site, the climate is dry and cold, the solar radiation is strong, and the temperature difference between day and night is large. Compared with the ordinary mass concrete, the experience about temperature control and crack prevention of hydropower plant in cold area is relatively scarce. There are few researches on temperature control and crack prevention of hydropower station, especial in cold area of China. So it is necessary to carry out the corresponding research.

Chen Xueyong carries on the test summary from the generalized comprehensive heat storage method, fumbles and sums up a set of concrete construction technology suitable for the special climate condition in the cold area[1]. Under the premise of ensuring the construction quality, not only the construction cost is reduced, but also the power generation target is achieved in advance. $\mathrm{Wu}$ Wenbin points out that the temperature control of concrete is a prominent problem in the concrete construction of hydropower station[2]. From the aspects of concrete production, transportation, pouring, maintenance and subsequent insulation, the temperature control measures of concrete suitable for hydropower station in cold area are explored. Jin Yimeng sums up the concrete construction methods in cold areas at home and abroad[3]. These engineering practices show that reasonable selection of temperature control standards, strict control of heat loss, the use of warm shed method combined with comprehensive heat storage method and using new materials to strengthen concrete surface maintenance can make the construction of concrete in low temperature environment better development and ensure the construction quality up to the design standard.

The previous research results and application experience can not provide sufficient and accurate temperature control suggestions to a new large engineering. In order to ensure the high crack resistance of concrete, a numerical simulaiton for temperature field and stress field of mass concrete in the lower part of BY

Corresponding author: sqiang2118@hhu.edu.cn 
station are applied. The simulation method is finite element method for 3D unstable temperature field and stress field[4]. The simulation considers not only the basic conditions of the power station and the layout of the powerhouse structure, but also the test of thermodynamic performance of concrete material, the plan of layered, the pouring block size. Based on the simulation results and engineering practice experience [1-3,5-9], practical temperature control measures are put forward to ensure high crack-resistance safety of structural concrete.

\section{Calculation principle and method}

\subsection{The basic theory for unsteady temperature field}

At an arbitrary point in concrete computation domain $\mathrm{R}$, unsteady temperature field $T(x, y, z, t)$ must meet the following control equation of heat conduction:

$$
\frac{\partial T}{\partial t}=\mathrm{a}\left(\frac{\partial^{2} T}{\partial x^{2}}+\frac{\partial^{2} T}{\partial \mathrm{y}^{2}}+\frac{\partial^{2} T}{\partial z^{2}}\right)+\frac{\partial \theta}{\partial \tau}
$$

Where $T$ is the temperature $\left({ }^{\circ} \mathrm{C}\right)$, a is the thermal diffusivity $\left(\mathrm{m}^{2} / \mathrm{h}\right), \quad \theta$ is the concrete adiabatic temperature $\left({ }^{\circ} \mathrm{C}\right), t$ is the time $(\mathrm{d}), \tau$ is the concrete age (d). The finite element method for the temperature field is found in reference [4].

\subsection{The method of pipe cooling temperatue field}

In reference [4], a set of approximate solution is given, that is, considering the cooling water pipe as a negative heat source and considering the cooling effect of the pipe in the average sense, the equivalent heat conduction square of concrete can be obtained.

$$
\frac{\partial T}{\partial \tau}=\mathrm{a}\left(\frac{\partial^{2} T}{\partial x^{2}}+\frac{\partial^{2} T}{\partial y^{2}}+\frac{\partial^{2} T}{\partial z^{2}}\right)+\left(\mathrm{T}_{0}-\mathrm{T}_{\mathrm{w}}\right) \frac{\partial \phi}{\partial \tau}+\theta_{0} \frac{\partial \varphi}{\partial \tau}
$$

Where $\mathrm{T}_{0}$ is the initial temperature of concrete $\left({ }^{\circ} \mathrm{C}\right), \mathrm{T}_{\mathrm{W}}$ is the water temperature $\left({ }^{\circ} \mathrm{C}\right), \phi$ is a function considering the effect of initial temperature difference $\left({ }^{\circ} \mathrm{C}\right), \varphi$ is a function considering the effect of adiabatic temperature rise of concrete $\left({ }^{\circ} \mathrm{C}\right)$.

\subsection{The basic theory for temperature stress field}

The strain increment of concrete under complex stress condition includes elastic strain increment, creep strain increment, temperature strain increment, dry shrinkage strain increment and autogenous volume strain increment, therefore:

$$
\left\{\Delta \varepsilon_{n}\right\}=\left\{\Delta \varepsilon_{n}^{e}\right\}+\left\{\Delta \varepsilon_{n}^{c}\right\}+\left\{\Delta \varepsilon_{n}^{T}\right\}+\left\{\Delta \varepsilon_{n}^{S}\right\}+\left\{\Delta \varepsilon_{n}^{0}\right\}
$$

Where $\left\{\Delta \varepsilon_{n}^{e}\right\}$ is elastic strain increment, $\left\{\Delta \varepsilon_{n}^{c}\right\}$ is creep strain increment, $\left\{\Delta \varepsilon_{n}^{T}\right\}$ is temperature strain increment, $\left\{\Delta \varepsilon_{n}^{S}\right\}$ is dry shrinkage strain increment, $\left\{\Delta \varepsilon_{n}^{0}\right\}$ is autogenous volume strain increment. The finite element method for the temperature stress field is found in reference [4].

\section{Calculation model and main parameters}

There are four units in BY Station. Taking one of the main workshop section and the outlet section as the calculation model. The structure of the station unit is basically symmetrical and the half of the unit is acceptable for calculation. The overall computational grid is shown in Fig. 1. The finite element number and node number of the finite element model are 129477 and 143932 respectively. The calculation grid of concrete structure is shown in Figs. 2 and 3. The number of elements of the half concrete structure is 94172 and the number of joints is 106595 . For different pouring blocks, the material number is represented by different colors in the drawing. The arrangement of cooling water pipes is shown in Fig. 4.

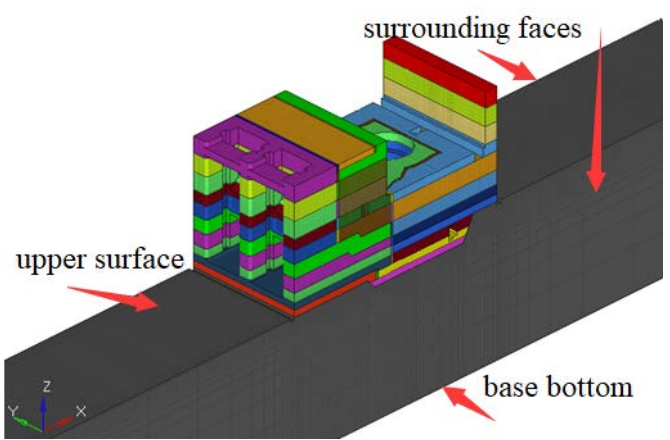

Fig. 1. Whole model

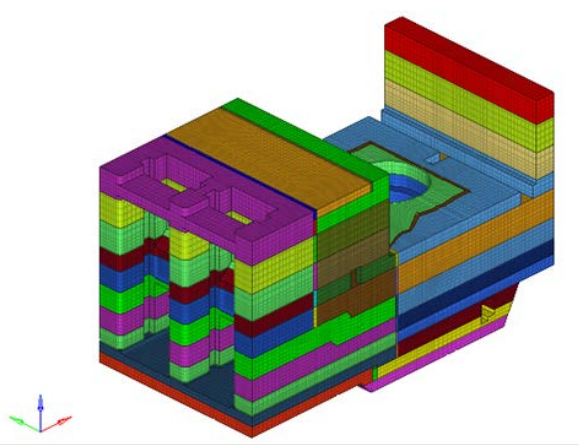

Fig. 2. Finite element model of concrete structure

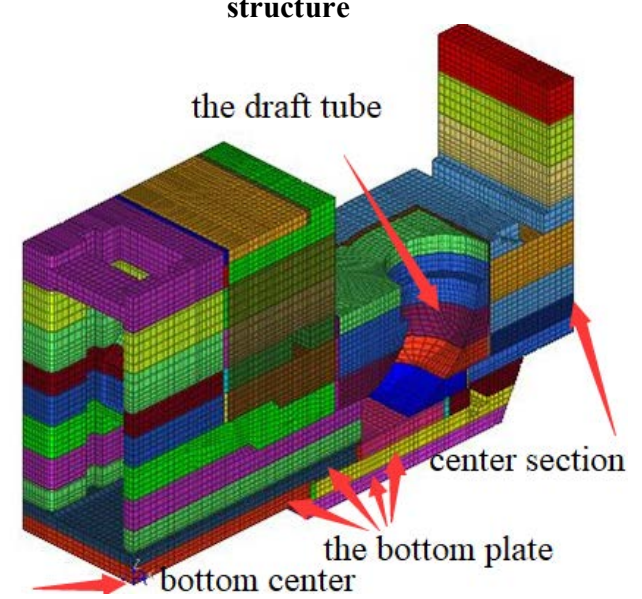

Fig. 3. Finite element model of half concrete structure 


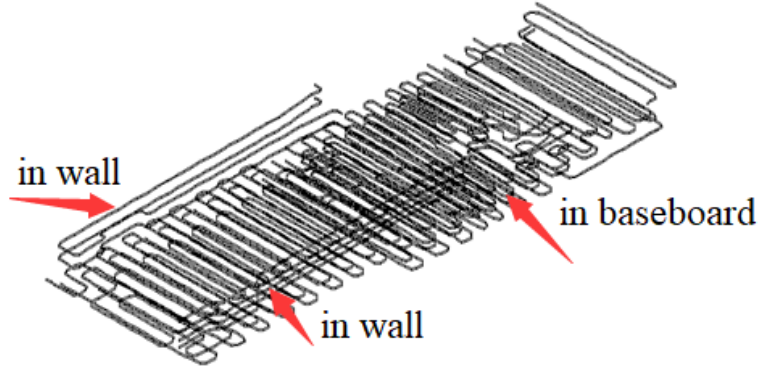

Fig. 4. Cooling pipes in baseboard and wall

In the simulation calculation, the origin of the model coordinates is located at the bottom center of the bottom plate of the unit. The $\mathrm{Z}$ axis is vertical, the $\mathrm{X}$ axis is pointing upstream, and the $\mathrm{Y}$ axis is perpendicular to the current direction according to the right hand spiral rule, pointing to the right bank. The XOZ plane (the face of $\mathrm{Y}=0 \mathrm{~m})$ is the center section of the machine.
Boundary conditions[10-11]: In the temperature field simulation, it is assumed that the bottom and the surroundings of the foundation are insulated boundary, and the other side is the heat exchange boundary. In the calculation of the stress field, the base bottom and surrounding faces are applied with normal constraint, the upper surface are free. For the concrete structure, the normal constraint is applied on the symmetry plane and the other suface is free.

The annual average daily temperature variation is calculated as follows:

$$
T_{a}(t)=8.75+8.75 \times \cos \left[\frac{\pi}{6}(t-6)\right], t \text { for the month }
$$

The whol model contains 3 types concrete and 1 type base rock. The main thermal and mechanical parameters are shown in Table 1.

Table 1. Thermal and mechanical parameters of the materials

\begin{tabular}{|c|c|c|c|c|c|c|c|}
\hline Material & $\begin{array}{c}\text { Thermal } \\
\text { Conductivity } \\
\lambda\end{array}$ & $\begin{array}{c}\text { Adiabatic } \\
\text { temperature } \\
\text { rise final value } \\
\theta^{0}\left({ }^{\circ} \mathbf{C}\right)\end{array}$ & $\begin{array}{c}\text { Final value of } \\
\text { autogenous } \\
\text { volume } \\
\text { deformation } \\
\left.\varepsilon\left(\mathbf{m} \cdot{ }^{\circ} \mathrm{C}\right)\right)\end{array}$ & $\begin{array}{c}\text { Coefficient of } \\
\text { linear } \\
\text { expansion } \\
\alpha\left(\times \mathbf{1 0}^{-6} /{ }^{\circ} \mathrm{C}\right)\end{array}$ & $\begin{array}{c}\text { Poisson's } \\
\text { ratio } \\
\mu\end{array}$ & $\begin{array}{c}\text { Density } \\
\rho \\
\left(\mathrm{kg} / \mathrm{m}^{3}\right)\end{array}$ & $\begin{array}{c}\text { Final } \\
\text { elastic } \\
\text { modulus } \\
E_{0}(\mathbf{G P a})\end{array}$ \\
\hline $\mathrm{C}_{90} 30 \mathrm{~W} 8 \mathrm{~F} 200$ & 9.720 & 24.43 & $-38,30$ & 8.655 & 0.167 & 2422 & 34.7 \\
\hline $\mathrm{C}_{28} 30 \mathrm{~W} 8 \mathrm{~F} 200$ & 9.364 & 41.52 & -64.60 & 9.364 & 0.167 & 2382 & 37.4 \\
\hline $\mathrm{C}_{28} 30 \mathrm{~W} 4 \mathrm{~F} 150$ & 9.364 & 41.52 & -72.59 & 9.364 & 0.167 & 2382 & 37.5 \\
\hline Foundation & 10.505 & 0.00 & 0.00 & 7.000 & 0.23 & 2630 \\
\hline
\end{tabular}

Explanatory notes:

$\mathrm{C}_{90} 30$ W8F200: Concrete reaches design strength 30 at 90 days; Impervious grade is 8; Freeze resistance rating is 200, that is to say, concrete can resist 200 freeze-thaw cycles.

The meanings of other concrete indicators can be found in the above explanatory analogy

\section{Calculation results analysis}

On the basis of case 1 without any temperature control measures, the most optimal case 5 was born by compositive measures such as controlling pouring temperature, preservation of concrete surface and reasonable cooling pipes. The calculation conditions of case 1 to 5 are given briefly as follows.

Csae 1: The concrete is poured without any temperature measures.

Case 2: Take control of the pouring temperature on the base of case 1 . It is set as following not lower than $6{ }^{\circ} \mathrm{C}$ in winter, $12{ }^{\circ} \mathrm{C}$ in strong constraining area in summer, $14^{\circ} \mathrm{C}$ in weak constraining area and $16^{\circ} \mathrm{C}$ in free area.

Case 3: Preservation of concrete surface is taken on the base of case 2. The permanent exposed surface of concrete is insulated until the end of the first winter, and the temporary storefront of concrete is kept warm until the upper layer of concrete is covered. The equivalent exothermic coefficient of concrete after heat preservation is $100 \mathrm{KJ} /\left(\mathrm{m}^{2} \mathrm{~d}^{\circ} \mathrm{C}\right)$.

Case 4: On the base of case 3 , water cooling measures are adopted. Under the corridor layer, the vertical spacing of the pipe is the thickness of the pouring layer and the horizontal spacing is $1.5 \mathrm{~m}$. Using HPDE high density polyethylene plastic pipe, the inner diameter is $28 \mathrm{~mm}$. Using low temperature water at $12{ }^{\circ} \mathrm{C}$ for 20 days cooling, the flow direction is changed once every 24 hours. The flow rate of the first 6 days is $1.5 \mathrm{~m}^{3} / \mathrm{h}$, then, the flow rate is reduced to $0.75 \mathrm{~m}^{3} / \mathrm{h}$. The temperature drop rate is not more than $0.5^{\circ} \mathrm{C} / \mathrm{d}$.

Case 5: On the basis of case 4, the cooling water temperature is reduced to $10{ }^{\circ} \mathrm{C}$, and the pipe interval in the bottom plate is adjusted to $1.0 \mathrm{~m}$.

Based on finite element method and program for 3D unstable temperature field and stress field, 5 cases comparative calculation and analysis are applied. Due to space limitations, only the results of case1 under natural measures and results of the most optimal case 5 are shown in Figure 5 to Figure. 12. The tipical sections 
$(\mathrm{Y}=5.0 \mathrm{~m})$ shown in Fig.5 to Fig.8 are located in the center section of the half unit, and the tipical point shown in Fig.9 to Fig.12 is located in the center of the baseboard of the draft tube.

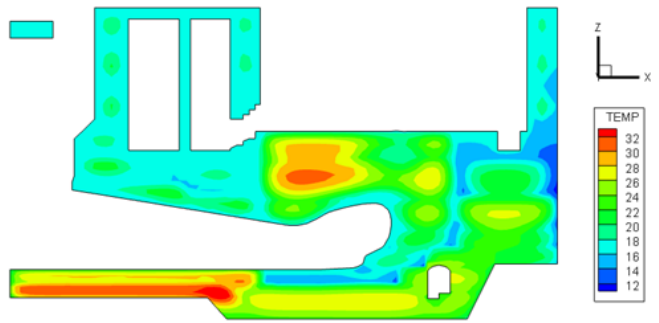

Fig. 5. Temperature countour of the center section in case $1 /{ }^{\circ} \mathrm{C}$

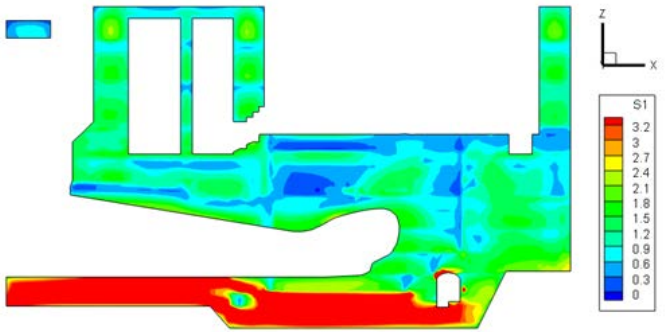

Fig. 6. The first principle stress countour of the center section in case $1 / \mathrm{MPa}$

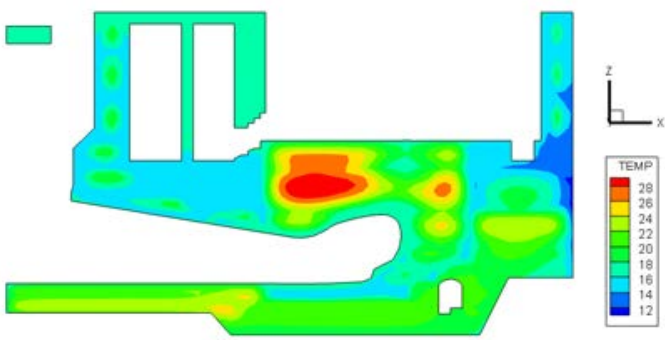

Fig. 7. Temperature countour of the center section in case $5 /{ }^{\circ} \mathrm{C}$

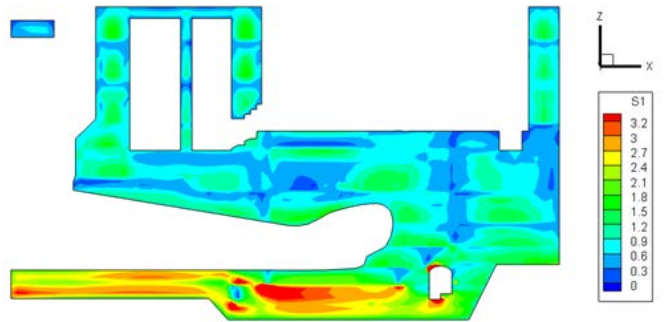

Fig. 8. The first principle stress countour of the center section in case $5 / \mathrm{MPa}$

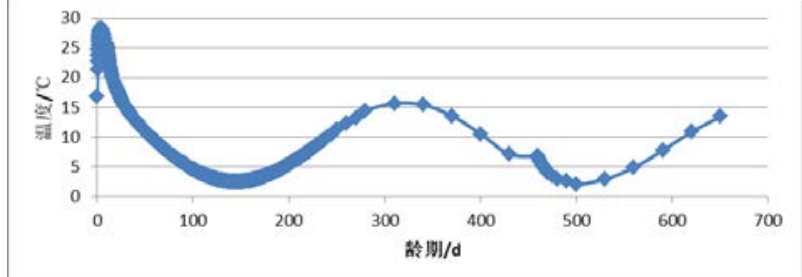

Fig. 9. Curve of temperature at midpoint of baseboard (case1)

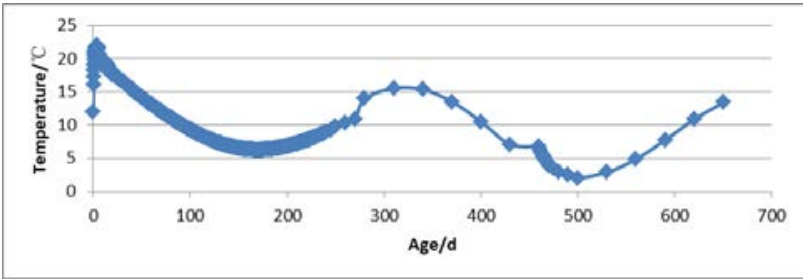

Fig. 10. Curve of temperature at midpoint of baseboard (case5)

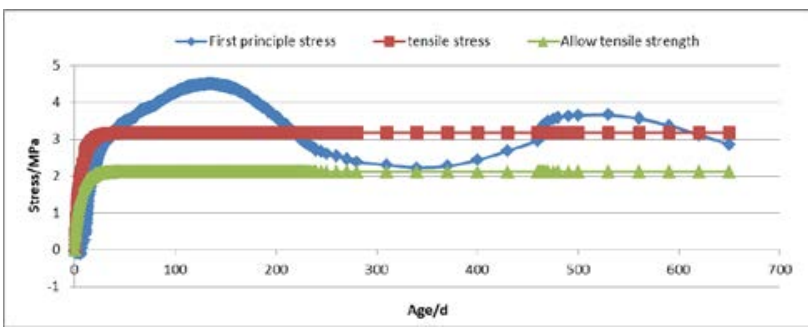

Fig. 11. Curve of the first principal stress at midpoint of baseboard(case1)

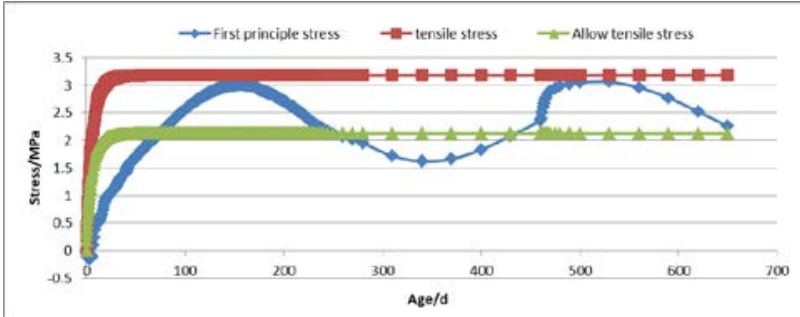

Fig. 12. Curve of the first principal stress at midpoint of baseboard (case5)

From the results of case 1 to case 5 and the Fig. 5 to Fig. 12, some conclusions or discussion can be drawn as follow.

(1) In the early stage of concrete pouring, the temperature rises rapidly due to the hydration of cement. The maximum temperature of case 1 in the baseboard is over $32{ }^{\circ} \mathrm{C}$ due to pouring temperature is high in summer.

(2) Because the peak value of internal temperature is high, when the temperature of concrete drops to the lowest value in winter, the shrinkage of concrete tries to reach the maximum value. Under the mutual restraint of foundation and structure itself, the concrete can not completely carry out free shrinkage. The parts of these attempted contractions that do not contract freely are converted into tensile stress.

(3) It can be seen from Fig. 6 and Fig. 11 that the tensile stress in the middle of the baseboard is the largest. The maximum tensile stress of the baseboard is 4.56 $\mathrm{MPa}$. The maximum tensile stress of the draft tube reaches 4.52 $\mathrm{MPa}$. Most of the maximum tensile stress of the bottom plate of the workshop exceeds the range of tensile strength of $\mathrm{C} 30$. 
(4) It can be seen from the temperature countour of center section in Fig. 5 and Fig. 7 that the maximum temperature of the baseboard of BY station is obviously reduced by taking comprehensive measures such as controlling pouring temperature, holding the concrete surface and optimizing the arrangement of cooling water pipes. Fig.9 and Fig. 10 show that the pouring temperature decreases from $16.7{ }^{\circ} \mathrm{C}$ to $12{ }^{\circ} \mathrm{C}$ and the maximum temperature of midpoint of baseboard decreases from $28.3{ }^{\circ} \mathrm{C}$ to $22.0^{\circ} \mathrm{C}$.

(5) From Fig.5 to Fig. 12 we can see that due to the decrease of temperature peak value and internal and external temperature difference, the overall tensile stress in the concrete floor of the workshop decreases in the later stage. Fig. 11 and 12 show that the maximum tensile stress in the baseboard decreases from 4.50 MPa to 3.06 $\mathrm{MPa}$, which has meeted the requirements of tensile strength of $\mathrm{C}_{28} 30$ concrete.

(6) Under the comprehensive temperature control measures of controlling the pouring temperature surface insulation and optimizing the arrangement of cooling water pipes, the tensile stress of the powerhouse is basically within the range of tensile strength of $\mathrm{C}_{28} 30$ concrete except some local stress concentration area. Case 5 is relatively optimal.

\section{Recommended temperature control indexes}

Based on the numerical simulation results, combined with practical experience, the following temperature control indexes are recommended.

(1) The casting temperature should not be lower than $6{ }^{\circ} \mathrm{C}$ in winter, and should not be higher then $12{ }^{\circ} \mathrm{C}$ in strong constraining area in summer, $14{ }^{\circ} \mathrm{C}$ in weak constraining area and $16{ }^{\circ} \mathrm{C}$ in free area.

(2) The maximum temperature in the strong constraining area should not be higher than $26{ }^{\circ} \mathrm{C}$ for $\mathrm{C}_{28} 30$, others should not be higher than $23^{\circ} \mathrm{C}$. When the concrete is in the weaken constraining area, the maximum temperature limit is $30^{\circ} \mathrm{C}$. When the concrete is in the free area, the maximum temperaturelimit is $40{ }^{\circ} \mathrm{C}$.

(3) Concrete temperature drop rate should not exceed $0.5^{\circ} \mathrm{C} / \mathrm{d}$.

(4) Internal and external temperature difference should be limited in $15^{\circ} \mathrm{C}$.

(5) Corridor should not cut off a casting block partly. Besides, it is suggested that for the weak part of concrete structure around the corridor, the anti-crack steel bar should be added.

\section{Conclusion}

Based on the simulation analysis, and combined with the engineering experience, the scheme of temperature control and crack prevention is put forward in the optimized case. The mainly measures are controlling pouring temperature, insulation of concrete surface and pipe cooling, block partition and extra steel bar reinforcement. Due to the cold climate and large scale structure, the values of temperature indexes are sharply lower than that of ordinary hydropower station mass concrete. Measures and indexes in this paper may provide some reference to similar large hydropower station workshop in cold area.

\section{Acknowledgements}

This work was financially supported by Study on Temperature Control and Crack Prevention of Mass Concrete Constructed in Cold Area (KY2018-SD-02) and the National Natural Science Foundation of China (51679074).

\section{References}

1. X. Y. Chen. Gansu Water Resources and Hydropower Technology. Vol. 50, No. 10(2014), P. 58.

2. W. B. Wu. Low Carbon World. Vol. 14, No. 48(2017), p. 74.

3. Y. M. Jing, H. S, Zhu, D. H. Huang. Advances in Science and Technology of Water Resources. Vol.33, No. 4(2013), p. 89.

4. B. F. Zhu. Beijing: China Water Power Press. 2009.

5. X.Y. Chen. Gansu Water Resources and Hydropower Technology. Vol. 50, No. 10(2014), p. 58.

6. Y. H. Lei, W. Q. Ta. Water Conservancy and Hydropower Construction. Vol. 4, No.04 (2012), p. 6.

7. T. G. Myers, N. D. Fowkes, et al. Journal of Engineering Mechanics. Vol. 135, No. 12(2009), p. 1375 .

8. P. Lin, Q. B. Li, P. Y. Jia. Mathematical Problems in Engineering. Vol. 2014, No. (2014), p. 1.

9. Y. J. Bie, S. Qiang, S. Xiao, et al. Construction and Building Materials. Vol. 142, No. (2017), p.514.

10. S. W. Ji, Y. M. Zhu, P. Xu, L.Guo: Journal of China Three Gorges University (Natural Scienced). Vol. 30, No. 2(2008), p. 12.

11. J. Q. Deng, Y. M. Zhu, P. Xu, L. Guo: Journal of China Three Gorges University (Natural Sciences). Vol.30, No. 5(2008), p. 8. 